\title{
Correction to: More Than You Expect: Priors Influence on the Adoption of Intentional Stance Toward Humanoid Robots
}

\author{
Jairo Perez-Osorio, Serena Marchesi, Davide Ghiglino, Melis Ince, \\ and Agnieszka Wykowska
}

\section{Correction to: \\ Chapter "More Than You Expect: Priors Influence on the Adoption of Intentional Stance Toward Humanoid Robots" in: M. A. Salichs et al. (Eds.): Social Robotics, LNAI 11876, https://doi.org/10.1007/978-3-030-35888-4_12}

Unfortunately, the authors of this article had failed to add an acknowledgement to their contribution. This missing acknowledgement was added to the article and reads as follows:

Acknowledgement:

This work received support from the European Research Council (ERC) under the European Union's Horizon 2020 research and innovation program (grant awarded to AW, titled "InStance: Intentional Stance for Social Attunement." G.A. No: ERC-2016StG-715058). 